\title{
O RECONHECIMENTO DO TERCEIRO GÊNERO: UMA RELEITURA DO PRINCÍPIO DA DIGNIDADE DA PESSOA HUMANA COMO CLÁUSULA GERAL DO DIREITO DA PERSONALIDADE
}

\author{
Jamille Bernardes da Silveira Oliveira dos Santos* \\ Valéria Silva Galdino Cardin*
}

RESUMO: O presente artigo se propõe a analisar a proteção jurídica dispensada às pessoas intersexuais à luz do princípio da dignidade da pessoa humana como cláusula geral dos direitos da personalidade. A ausência de regulamentação jurídica acerca da situação dos indivíduos intersexuais os coloca em estado de vulnerabilidade. Assim, por meio de método teórico que consiste na consulta de obras, artigos de periódicos, documentos eletrônicos e legislação aplicável ao caso, tem-se por objetivo abordar a questão da intersexualidade e a possibilidade do reconhecimento do terceiro gênero pelo ordenamento jurídico brasileiro.

PALAVRAS-CHAVE: Direitos da Personalidade; Dignidade Humana; Direitos Fundamentais; Intersexo; Terceiro Gênero.

\section{THE THIRD GENDER RECOGNITION: A REVIEW OF THE HUMAN PERSON'S DIGNITY PRINCIPLE AS A GENERAL CLAUSE OF PERSONALITY LAW}

\begin{abstract}
This paper aims to analyze the legal protection of the intersex in the light of the principle of human dignity as a general clause of the personality rights. The absence of legal regulation regarding the situation of the intersex individuals puts them in a state of vulnerability. Thus, by means of a theoretical method, consisting of consulting works, journal articles, electronic documents and legislation applicable to the case, the objective is to address the issue of intersexuality and the possibility of recognizing the third gender in the brazilian legal system.
\end{abstract}

KEYWORDS: Personality Rights; Human Dignity; Fundamental Rights; Intersex; Third Genre.

\section{INTRODUÇÃO}

No Brasil, há menos de 200 (duzentos) anos a escravidão ainda existia, as mulheres só passaram a votar no ano de 1932 e a homotransfobia tornou-se crime equiparado ao

\footnotetext{
Mestranda em Ciências Jurídicas pelo Centro Universitário de Maringá (UNICESUMAR); Bolsista CAPES/PROSUP; Especialista em Direito e Processo Penal pela Universidade Paranaense (UNIPAR); Advogada; E-mail: jamillebernardes@gmail.com

* Pós-Doutora em Direito pela Universidade de Lisboa; Doutora e Mestre em Direito das Relações Sociais (PUCSP); Docente (UEM) e do Programa de Pós-Graduação em Ciências Jurídicas (UNICESUMAR); Advogada; E-mail: valeria@galdino.adv.br
} 
racismo somente em 2019. Em virtude deste atraso jurídico-legislativo, o nosso país lidera o ranking de violência contra pessoas LGBT e é o que mais mata transexuais no mundo. (QUEIROGA, 2018). O reconhecimento de uma pessoa, sem distinção de sexo, raça ou classe apenas ganhou amparo legal com o advento da atual Constituição Federal, momento em que a dignidade humana passou a ser um dos fundamentos da República Federativa do Brasil.

Ressalte-se que a ausência de representatividade política e social ainda assola muitos grupos, especialmente porque ainda imperam muitas rotulações e discriminações, de forma que tudo o que foge à "normalidade" imposta pela heteronormatividade continua sendo marginalizado e ignorado pela sociedade. Neste espectro, a presente pesquisa tem por objetivo abordar a questão da intersexualidade e a possibilidade de adoção de um terceiro gênero sob o amparo da proteção da dignidade da pessoa humana e dos direitos da personalidade.

Por habitarem corpos não reconhecidos, que fogem do binarismo "homem-mulher" sob o qual está firmada toda a sociedade, os intersexos sempre foram banalizados e expostos diante de uma normativa que não os representa. A intersexualidade é um fenômeno social, contudo, poucas são as pesquisas que abordam esta questão, principalmente na seara do direito, fato que dificulta o reconhecimento das pessoas com esta condição física perante a sociedade e acaba por renegá-los à invisibilidade.

Portanto, ante a ausência de regulamentação específica que forneça regras para o trato e para o reconhecimento destas pessoas, a proposta deste trabalho mostra-se válida como mecanismo de discussão e de provocação do Poder Judiciário para que este se manifeste acerca do assunto. Assim, no intuito de dar visibilidade à questão da intersexualidade, o presente trabalho, por meio do método teórico, que consiste na consulta de livros, artigos de periódicos, documentos eletrônicos, legislação e jurisprudência aplicáveis ao caso, propõe a análise da intersexualidade como um terceiro gênero e a sua consequente proteção jurídica.

\section{A PASSAGEM dO ESTADO LIBERAL PARA O SOCIAL E A CONSTRUÇÃO DA DIGNIDADE DA PESSOA HUMANA COMO CENTRO DO ORDENAMENTO JURÍDICO BRASILEIRO}

A formação do Estado, tal como conhecemos hoje, se originou do constante rompimento de paradigmas socioculturais. De acordo com Thomas Khun (1997, p. 23), paradigmas são "as realizações científicas universalmente reconhecidas que, durante algum 
tempo, fornecem problemas e soluções modelares para uma comunidade". Dentre as muitas fases do Estado, destaca-se o período Moderno e as suas duas principais correntes de pensamento: o Liberalismo e o Socialismo, ambas de grande contribuição para a atual concepção dos direitos fundamentais.

Considerado o principal precursor do Estado Liberal, John Locke foi um grande crítico do Estado Monárquico, uma vez que para o filósofo o poder não poderia estar concentrado nas mãos de um único indivíduo, de forma que seria necessária uma divisão de poderes, bem como a separação da Igreja e do Estado, declarando-se, neste aspecto, favorável à liberdade religiosa. (SARMENTO, 2004).

Neste sentido, esclarece Daniel Sarmento (2004) que diferentemente de Charles Louis de Montesquieu, que sustentava a separação dos Poderes (Executivo, Legislativo e Judiciário), admitindo-se uma limitada interação entre estes, a qual denominou de "Sistema de Freios e Contrapesos" ${ }^{\prime}$, Locke acreditava que o Poder Legislativo, por representar os anseios da sociedade, deveria ser considerado superior aos demais poderes.

Isto porque, na perspectiva de Locke, o ser humano seria detentor de direitos $a$ priori, que deveriam ser respeitados pelos governantes (limitação à atuação estatal) e, do contrário, seria cabível, inclusive, o exercício de resistência. Ainda, o filósofo destacava que entres os direitos essenciais do indivíduo o de propriedade era o mais importante e o que demandava maior proteção por parte do Estado. O autor Noberto Bobbio resume os fundamentos liberais de Locke da seguinte forma:

[...] através dos princípios de um direito natural preexistente ao Estado, de um Estado baseado no consenso, de subordinação do poder executivo ao poder legislativo, de poder limitado, de direito de resistência, Locke expôs as diretrizes fundamentais do Estado liberal, concluindo o período das guerras civis na Inglaterra e abrindo o novo período que, através de Montesquieu, chegará às constituições dos estados americanos e à Revolução Francesa. Sua obra é a ponte de passagem do Estado liberal inglês para o continental. (BOBBIO, 2000, p. 64).

Para o Estado Liberal, a liberdade do indivíduo seria resguardada na medida em que este fosse capaz de exercer "autonomia negocial", ou seja, adquirir bens, contratar e dispor em contrato. Assim, esperava-se do Estado nas relações jurídicas entre os particulares uma ação

\footnotetext{
† Vide: MONTESQUIEU, Charles Louis de. Do Espírito das Leis. In: Coleção Os Pensadores - Montesquieu. São Paulo, Abril Cultural, 1973.
} 
reduzida, de forma a se ausentar "da esfera econômica, que permanecia à mercê das forças do mercado, limitando-se ao modesto papel de protetor da segurança interna e externa e da propriedade dos seus cidadãos". (SARMENTO, 2004, p. 29).

Como para esta corrente os direitos dos seres humanos estão concentrados no direito à propriedade, o problema da desigualdade social ganhou relevo e atenção, porquanto, aqueles que detinham maior poder aquisitivo estavam em vantagem em relação aos situados em posições sociais inferiores, circunstância que ocasionou na ruptura do Estado Liberal e o início da concepção do Estado Social.

Desta forma, faz-se necessário mencionar o pensamento de Karl Marx, principal nome do movimento socialista. Para ele, as ideias liberalistas não passavam de uma utopia, em que os indivíduos poderiam negociar entre si em paridade de condições, situação "totalmente contraditória com a realidade efectiva, que era antes a de indivíduos condicionados por constrangimentos econômico-sociais, negociando em posições desequilibradas". (HESPANHA, 1997, p. 221).

Ainda, Marx sustentava que não bastaria que o Estado abolisse as diferenças entre as classes, isto é, não seria suficiente a burguesia deixar de existir, de modo o fim das desigualdades oriundas da diferenciação de classes só seria possível diante de uma tomada de poder por meio de uma "revolução violenta". (LENIN, 1986, p. 23).

Em que pese o Estado Social seja fruto do Socialismo, com este não se confunde, visto que além de propor uma reviravolta das classes por meios agressivos, o Socialismo também se configurava como um sistema extremista, tal como o Liberalismo já havia se mostrado, sendo que, neste caso, o sistema socialista fazia com que o cidadão sacrificasse a propriedade privada em nome do coletivo. A consequência deste cenário era o massacre das liberdades individuais e, por lógica, um risco para as minorias que, inúmeras vezes, terminaram sufocadas pelos desejos da maioria.

Para o Estado Social, os direitos basilares do Estado se encontram firmados na representação do indivíduo perante o corpo social, de forma que prevalece o coletivo em detrimento do individual, e o Estado, antes mero figurante, passa a ter papel ativo, no ensejo de permitir que todos tenham o mínimo de dignidade salvaguardada. Neste viés, os direitos fundamentais deixaram de ser meros limites de exercício do "poder político, o sea, garantías negativas de los intereses individuales, para devenir un conjunto de valores o fines directivos de la acción positiva de los poderes públicos". (LUÑO, 1995, p. 21). 
Assim, se no Estado Liberal o Código Civil era o centro do ordenamento, com a entrada em vigor do Estado Social as constituições passam a figurar como âmago e referenciais a serem seguidos, de forma que todos os demais mecanismos legais passaram a ser interpretados segundo tal ótica. A necessidade de um Estado capaz de garantir direitos básicos e inerentes a todos os seres humanos, independente de quaisquer distinções, surgiu como reação às atrocidades cometidas na Segunda Guerra Mundial.

Ademais, a busca pela proteção do ser humano como ente individual e, ao mesmo tempo, parte de uma coletividade, cuja dignidade precisa ser a máxima de todo direito e dever, foi reforçada pelo surgimento de instrumentos internacionais, sendo o de maior destaque a Declaração Universal dos Direitos Humanos, de 1948. De acordo com o art. $1^{\circ}$ deste documento, "todos os seres humanos nascem livres e iguais em dignidade e direitos. São dotados de razão e consciência e devem agir em relação uns aos outros com espírito de fraternidade”. (DECLARAÇÃO UNIVERSAL DOS DIREITOS HUMANOS, 1948).

Tal fundamentação principiológica influenciou também a evolução do ordenamento jurídico-político brasileiro, que tratou de acentuar a importância da proteção da dignidade da pessoa humana como o elemento essencial para a conceituação de um Estado que tenha por fito ser Democrático de Direito. E é em razão disso que estipula o art. $1^{\circ}$, inciso III, da Constituição Federal, que a dignidade da pessoa humana é fundamento indispensável da República Federativa do Brasil. (BRASIL, 1988). Nesse contexto, é cediço que tentar definir a dignidade da pessoa humana como um conceito certo e fechado seria uma tarefa árdua e, talvez, de pouca valia, já que esta se revela em cada caso concreto. Para Ingo Sarlet:

[...] a dignidade - ao menos de acordo com o que parece ser a opinião largamente majoritária - independe das circunstâncias concretas, já que inerente a toda e qualquer pessoa humana, visto que, em princípio, todos - mesmo o maior dos criminosos - são iguais em dignidade, no sentido de serem reconhecidos como pessoas - ainda que não se portem de forma igualmente digna nas suas relações com seus semelhantes, inclusive consigo mesmos. (SARLET, 2013, p. 21).

Logo, a dignidade da pessoa humana se sobrepõe ao próprio direito à vida, pois, sem o primeiro, não há que se falar no segundo e, seguindo este raciocínio, resta nítido que este princípio é o cerne de todo o direito brasileiro, de modo que todas as decisões e interpretações devem se dar no sentido de que a condição de dignidade da pessoa seja protegida como bem de maior valor, cuja ausência implica na própria inexistência do Estado. 


\section{DA DIGNidAde DA PESSOA HUMANA COMO CLÁUSULA GERAL dOS DIREITOS DA PERSONALIDADE}

Entende-se por direitos da personalidade a proteção jurídica dispensada às características psicofísicas e morais inerentes à formação do indivíduo, sem as quais esta não poderia existir em sua plenitude. Tratam-se, portanto, de direitos subjetivos, naturais e $a$ priori do ser humano. É, portanto, “o direito da pessoa de defender o que é próprio, como a vida, a identidade, a liberdade, a imagem, a privacidade, a honra, etc.” (DINIZ, 2011, p. 133134). Assim, são direitos essenciais, posto que sem eles todos os demais direitos subjetivos restariam sem importância para o indivíduo (CUPIS, 2008), já que estes formam a "medula da personalidade" (BITTAR, 2004, p. 06), sem a qual não há respeito à dignidade humana.

Nas palavras de Antonio Gullón e de Luis Diéz-Picazo, "la persona no es exclusivamente para el Derecho civil el titular de derechos y obligaciones o el sujeto de relaciones juridicas". Ainda, para o autor, estas relações “debem contemplar y proteger sobre todo a la persona considerada en sí misma, a sus atributos físicos y morales, a todo lo que suponga desarrollo y desenvolvimiento de la misma”. (DIÉZ; GULLÓN, 1988, p. 338).

Historicamente, a noção jurídica de personalidade surgiu no direito romano clássico como qualidade daquele que reunisse em si três características: "status libertatis, status civitatis e o status familiae". (SOUZA, 1995, p. 47). Ou seja, a personalidade era atributo daquele que fosse reconhecido como livre, capaz de exercer atos na sociedade civil e membro paterfamilias (patriarca), ou que estivesse agindo sob os interesses de um grupo familiar. Por meio desta perspectiva, o direito romano estabeleceu a possibilidade de uma actio iniuriarum, que consistia da possibilidade de ingressar com ação contra toda espécie de atentado à pessoa física ou à moral do cidadão. (TEPEDINO, 2004).

A Constituição Federal de 1988 evidenciou a necessidade de proteção à personalidade humana ao garantir direitos relativos ao nome, à honra, à intimidade, à imagem e à integridade física. Entretanto, somente com a entrada em vigor do Código Civil de 2002 é que a expressão "personalidade" foi inclusa no arranjo jurídico brasileiro, em primeiro plano, como forma de delimitar o momento em que um ser passa a ter reconhecida a sua personalidade/existência, mesclando-se este conceito ao de capacidade civil e, posteriormente, o referido códex tratou de abarcar as características dos direitos da personalidade. 
Deste modo, em razão da sua finalidade, para Bittar (2001, p. 05) os direitos da personalidade são dotados "de certas particularidades, que lhes conferem posição singular no cenário dos direitos particulares, que avultam, desde logo, as seguintes: a intransmissibilidade e a irrenunciabilidade", situando-se estas, inclusive, como limites ao exercício do próprio titular, conforme preconiza o art. $11^{\circ}$ do Código Civil. (BRASIL, 2002).

Ainda, no entendimento de Silvio Venosa (2011), os direitos da personalidade seriam direitos absolutos, intransmissíveis, irrenunciáveis, ilimitados, imprescritíveis, impenhoráveis e inexpropriáveis, tendo em vista que estes possuem as seguintes características:

\begin{abstract}
(a) são inatos ou originários porque se adquirem ao nascer, independente de qualquer vontade; (b) são vitalícios, perenes ou perpétuos, porque perduram por toda a vida. Alguns se refletem até mesmo após a morte da pessoa. Pela mesma razão são imprescritíveis porque perduram enquanto perdurar a personalidade, isto é, a vida humana. $\mathrm{Na}$ verdade, transcendem a própria vida, pois são protegidos também após o falecimento; são também imprescritíveis; (c) são inalienáveis, ou, mais propriamente, relativamente indisponíveis, porque, em princípio, estão fora do comércio e não possuem valor econômico imediato; (d) são absolutos, no sentido de que podem ser opostos erga omnes. Os direitos da personalidade são, portanto, direitos subjetivos de natureza privada. (VENOSA, 2011, p. 171).
\end{abstract}

Já para Elimar Szaniawski (2005), os direitos da personalidade são originários e não inatos, na medida em que considerá-los como inatos implicaria no reconhecimento de que estes seriam anteriores ao ordenamento jurídico. Contudo, visto que a forma de enxergar o ser humano e as suas relações sociais se modifica ao longo do tempo, a interpretação dos direitos também se altera e leva em conta o contexto social, econômico, político, etc.

Ademais, em relação ao caráter absoluto dos direitos da personalidade, Fernanda Borghetti Cantali esclarece que este atributo não se relaciona com o conteúdo do direito em si, tampouco pode ser compreendido "como gerador de imposição ilimitada e em qualquer circunstância. Na perspectiva relacional, do ser com os outros, o caráter absoluto dos direitos da personalidade se relativiza”. (2009, p. 136).

Para a autora em comento, há a possibilidade de disposição e de renúncia dos direitos da personalidade, é o caso da opção pela eutanásia, circunstância em que a pessoa dispõe do direito à vida em prol da garantia de uma morte digna, que, para ela, possui significado mais elevado do que o prolongamento da vida a qualquer custo e lastreado pelo sofrimento. Há também o caso dos reality shows, em que as pessoas, voluntariamente, abrem mão de sua privacidade e imagem. Em ambos os casos, nota-se a disposição de direitos da personalidade - tais como a vida, imagem e privacidade - pelo seu titular. (CANTALI, 2009, p. 136). 
Neste sentido, verifica-se que é possível a relativização dos direitos da personalidade desde que reste preservado o núcleo essencial do direito, caracterizado pela proteção à dignidade da pessoa humana. Isto porque a noção do que é essencial varia de pessoa para pessoa e possui intrínseca relação com o exercício da autonomia privada. Para Ingo Sarlet, a dignidade da pessoa humana é:

indissociável da ideia de direitos fundamentais, não apenas por figurar como fundamento deles, mas também porque todos os direitos fundamentais são exigências de concretização do princípio da dignidade da pessoa humana. Os direitos fundamentais guardam, ainda que com intensidades diversas, reflexos do princípio da dignidade da pessoa humana, já que todos remontam à ideia de proteção e desenvolvimento das pessoas. (SARLET, 2004, p.78-79).

Partindo deste princípio, para Eliminar Szaniawski, ainda que o ordenamento jurídico brasileiro tenha optado por descrever os direitos da personalidade de forma fragmentada (elegendo quais direitos condizem com a proteção da personalidade humana), ao prever a dignidade da pessoa humana como princípio essencial para a constituição do Estado, o legislador acabou por adotar uma tutela geral dos direitos da personalidade. Para o autor, "o princípio da dignidade da pessoa humana consiste, pois, no ponto nuclear, onde se desdobram todos os direitos fundamentais do ser humano". (SZANIAWSKI, 2004, p. 142).

Logo, "a doutrina do direito geral da personalidade pugna pelo reconhecimento de que a personalidade deve ser protegida de forma global, considerando a própria natureza da pessoa, que representa um valor unitário”. (GARCIA, 2007, p. 73). Assim, o ser humano deve ter a sua personalidade tutelada como um todo, a fim de lhe seja ofertada a proteção integral ao livre desenvolvimento.

\section{A DISSOCIAÇÃO DO BINÁRIO “GÊNERO E SEXO”}

As questões relacionadas à sexualidade sempre despertaram a curiosidade humana, que, de acordo com a época e o pensamento predominante, buscou representá-la por meio das artes. Do pecado ao estado da graça, a sexualidade se faz presente seja como plano de fundo ou como obra central. No livro de Gênesis (3:11), a Bíblia Sagrada associa o sexo a algo impuro e como fruto do pecado. Na referida passagem, Deus fala para o homem que a descoberta do próprio sexo estava diretamente associada a algo proibido: "Quem lhe disse que você estava nu? Por acaso você comeu da árvore da qual eu lhe tinha proibido comer?”. 
Esta visão bíblica sobre o sexo perdurou por muitos séculos. Contudo, o surgimento dos movimentos feministas colocou em xeque os padrões e conceitos de masculino e de feminino e até que ponto estes seriam suficientes para justificar os vários papéis dos homens e das mulheres na sociedade. Diante desse contexto, destacou-se a necessidade de aceitação dos diferentes tipos de feminilidade e de masculinidade, que questionam o conceito de supremacia do homem sobre a mulher. (FEITOSA, 2008, p. 07).

No início do século XX, os estudos de Simone de Beauvoir foram essenciais para a dissociação do gênero e do sexo, visto que a autora mostrou como estes dois termos são diferentes e, não necessariamente, o primeiro é definido pelo segundo. Beauvoir buscou entender a performática da mulher na sociedade e, apesar de aceitar as diferenças biológicas existentes entre homens e mulheres, não as entendia como determinantes para esclarecer os diferentes tratamentos dados a cada um dos sexos, de modo que a autora ressaltou a importância do contexto histórico e da construção social do gênero. (BEAUVOIR, 2009).

De igual modo, Joan Wallach Scott (1986) relacionou o surgimento da terminologia "gênero" com o início dos estudos feministas e, para ela, a abordagem destes termos estaria ligada a três posicionamentos teóricos: (i) à corrente feminista que buscava explicar as origens do patriarcado; (i) à corrente situada no interior de uma tradição marxista atrelada ao compromisso com as críticas feministas e (iii) ao pensamento pós-estruturalismo francês e às teorias anglo-americanas de relação do objeto.

Logo, embora socialmente os conceitos "sexo" e "gênero" sejam considerados sinônimos, tais termos não se confundem, vez que o primeiro é usado para designar o órgão genital propriamente dito e, portanto, possui relação biológica, distinguindo tradicionalmente o "feminino" do "masculino". Por outro lado, o gênero é mais abrangente e diz respeito à construção do que é ser "homem" e "mulher".

Já Judith Butler não só reconhece a dissociação do binarismo gênero-sexo, como o critica diante de uma profunda preocupação de que a afirmação constante do gênero como fruto de uma construção histórico-social também poderia passar a ser vista como um conceito fechado, caso não observasse a mutabilidade do ser. Seus estudos surgem como um contraposto à teoria feminista clássica, pois, para Butler, os estudos sobre gênero e sexo ainda estavam presos à dicotomia homem-mulher:

[...] a ideia de que o gênero é construído sugere um certo determinismo de significados do gênero, inscritos em corpos anatomicamente diferenciados, sendo 
esses corpos compreendidos como recipientes passivos de uma lei cultural inexorável. Quando a 'cultura' relevante que 'constrói' o gênero é compreendida nos termos dessa lei ou conjunto de leis, tem-se a impressão de que o gênero é tão determinado e tão fixo quanto na formulação de que a biologia é o destino. Nesse caso, não a biologia, mas a cultura se torna o destino. (BUTTLER, 2003, p. 50).

Neste viés, tem-se que o gênero é algo infinitamente maior, e nas palavras de Dagmar Estermann Meyer, ele "propõe um afastamento de análises que repousam sobre uma ideia reduzida de papéis/funções de mulher e homem, para aproximar-nos de uma abordagem muito mais ampla". A autora também ressalta a necessidade de se considerar que as instituições sociais, os símbolos, as normas, os conhecimentos, as leis, as doutrinas e as políticas de uma sociedade "são constituídas e atravessadas por representações e por pressupostos de feminino e de masculino". (MEYER, 2003, p. 18).

Denota-se, desta feita, que o binarismo sexo-gênero alcança debates que ultrapassam a mera questão dos papéis sociais do feminino e do masculino, uma vez que estes conceitos afetam a própria conotação de sociedade, são modificados e modificam a realidade ao seu redor em igual proporção. Neste ponto, fundamental é ressaltar que não se busca com isto negar os corpos, a importância do sexo ou de algum modo ignorar que a anatomia corporal possui o seu peso na construção do ser humano, mas sim, que esta "implica comprender, sí, que son precisamente los discursos, los códigos, las representaciones que atribuyen el significado de diferente a los cuerpos y a las identidades". (LOURO, 2019, p. 01).

Neste sentido, como compreende Louro (1997, p. 24) “os sujeitos vão se construindo como masculinos ou femininos, arranjando e desarranjando seus lugares sociais, suas disposições, suas formas de ser e de estar no mundo". Dito isto, resta evidente a dissociação existente entre sexo e gênero e a forma como cada um contribui para a composição do indivíduo e de sua personalidade e essência.

\section{DA INTERSEXUALIDADE: A VISÃO DE UM TERCEIRO GÊNERO}

Como já mencionado, tem-se que a sexualidade desempenha papel crucial na vida do indivíduo e o gênero e as manifestações que dele derivam implicam diretamente em como o ser humano se porta perante a sociedade e em como ela lhe tratará. 
Assim, no Brasil muitos embates foram travados em busca do reconhecimento das diferentes orientações sexuais e identidades de gênero, e, graças a tais lutas, em março de 2018, por meio de Ação Direta de Inconstitucionalidade (ADI n. ${ }^{\circ}$ 4.275/2018), o Supremo Tribunal Federal (STF) decidiu que qualquer pessoa poderia, pela via extrajudicial, promover a mudança de seu nome e gênero no registro civil e, consequentemente, nos demais documentos oficiais, dispensando-se, para tanto, a realização de cirurgia de redesignação de sexo e/ou de outros documentos complementares, tais como laudos psicológicos e perícia médica. (POMPEU, 2018).

Além disto, também em 2018, a Organização Mundial de Saúde (OMS) reconheceu a despatologização da transexualidade, a qual antes figurava como doença mental e passou a figurar no campo da saúde sexual. Diante disso, todos países devem se adequar à mudança até

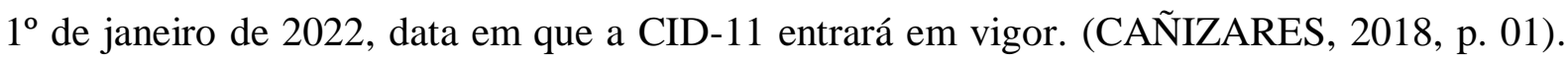
Neste contexto, salienta-se que já há países e localidades que admitem as variantes de expressões de gênero e sexualidade, é o caso do estado de Nova Iorque/EUA, que reconhece a existência de 31 (trinta e um) gêneros diferentes. (THEDIM, 2018).

Entretanto, mesmo com as citadas conquistas, a população LGBTIQ+ ainda vê muitos de seus direitos humanos básicos violados, o que a coloca em situação de vulnerabilidade. Atualmente, o Brasil adota a sigla LGBTI (lésbicas, gays, bissexuais, transexuais, transgêneros e intersexos), admitindo-se a variação LGBTQI+ (inserção da letra “Q” para representar a Teoria Queer; e do símbolo “+” na tentativa de reconhecer a existência de outras variantes). De todo modo, a adesão dos intersexuais ao movimento é algo recente e pouco aceito no âmbito nacional.

A intersexualidade é uma condição física caracterizada pela anomalia na diferenciação sexual, ou seja, o indivíduo possui características relacionadas a ambos os sexos amplamente conhecidos (feminino e masculino), o que impossibilita a sua inserção em apenas um destes grupos. (FRASER; LIMA, 2012). De acordo com Andrea Tavares Maciel-Guerra:

a intersexualidade humana constitui um fenômeno orgânico, oriundo de um desequilíbrio entre os fatores e eventos responsáveis pela determinação e diferenciação sexuais, que se configura quando o indivíduo apresenta ambiguidades, anomalias ou incongruências no componente biológico da sua identidade sexual, ou seja, no seu sexo cromossômico, endócrino e/ou morfológico. (MACIEL-GUERRA apud FRASER; LIMA, 2012, p. 01). 
Até o início dos anos 2000, os intersexos eram chamados de hermafroditas, termo pejorativo que deixou de ser utilizado a partir da Resolução n. ${ }^{\circ}$ 1.664/2003, do Conselho Federal de Medicina (CFM), que editou as normas técnicas necessárias para o tratamento de pacientes portadores de anomalias de diferenciação sexual (ADS). De acordo com o documento, serão consideradas como ADS os casos de genitália ambígua, ambiguidade genital, intersexo, hermafroditismo verdadeiro, pseudo-hermafroditismo (masculino ou feminino), disgenesia gonadal, sexo reverso, etc. (CFM, 2003).

Em alguns casos, a anomalia é identificada logo após o nascimento da criança, quando verificado que esta possui a genitália ambígua, de forma que não é possível defini-la como menina ou menino. Esta constatação gera grande aflição nos pais do que, por "não saber como identificar o próprio filho, que nome dar a ele, com que cor de roupa vesti-lo, gera angústias e, por vezes, sentimento de rejeição e até repulsa”. (DIAS, 2018, p. 24).

No Brasil, é comum que nestes casos seja realizada a cirurgia corretiva, no intento de adequar o bebê a um dos sexos. Para isso, são realizados vários exames no intento de afirmar qual é o sexo predominante. Todavia, como adverte Zucker (2002, p. 3), no meio médico há aqueles que criticam o uso desta cirurgia corretiva logo após o nascimento da criança, pois seria ela "merely cosmetic, perhaps akin to a face-lift, and not medically necessary, and that it is permormed primarily to appease anxious parentes". Ainda, muitos profissionais alertam para o fato de que uma cirurgia deste nível, realizada ainda na primeira infância, poderia desencadear disfunções sexuais na fase adulta. (ZUCKER, 2002).

Visto deste aspecto, as cirurgias corretivas denotam evidente ofensa aos direitos da criança, eis que representam afronta a sua integridade física, psíquica e moral, além de restringir-lhe o direito ao livre desenvolvimento, umas das facetas dos direitos da personalidade. Outro problema é o que surge na hora da lavratura do registro de nascimento, porquanto a indicação do sexo/gênero é imprescindível para este fim, motivo pelo qual os médicos se embrenham numa "sacra" missão de definir o sexo do menor o quanto antes.

Em virtude disto, tramita perante o Congresso Federal o Projeto de Lei (PL n. ${ }^{\circ}$ $5255 / 2016$ ) com o intento de disciplinar o registro civil do recém-nascido que apresente esta anomalia, permitindo que conste no documento a inscrição "indefinido" ou "intersexo" no lugar da indicação do sexo. (BRASIL, 2016). A díspar do que ocorre no Brasil, vários países, entre eles, a Austrália, a Alemanha, Bangladesh, a Nova Zelândia, o Nepal, o Paquistão, a 
Índia, o Canadá, Malta e o Quênia adotaram a possibilidade de um terceiro gênero como saída para o registro de pessoas que se enquadrem como intersexuais. (ARPEN BRASIL, 2017).

Desta forma, importa esclarecer que o terceiro gênero não se confunde com o gênero neutro, pois este corresponde às pessoas que não se identificam nem como homem nem como mulher. "A existência de somente dois gêneros fazia com que os indivíduos, que não se identificavam dentro deste estereótipo, fossem compelidos a assumir um deles frente à sociedade”. (SCHMITZ; STEVANELLI, 2019, p. 393).

Sem adentrar na questão do gênero neutro, o qual se mostra como uma vertente da Teoria Queer e busca uma visão do mundo que não se fixe no binarismo "homem-mulher", a opção por um terceiro gênero, no caso de pessoas identificadas como intersexo, mostra-se uma medida razoável no intento de garantir os direitos inerentes ao ser humano, que, como relatado antes, é digno em sua essência, devendo o ordenamento protegê-lo neste sentido.

$\mathrm{O}$ reconhecimento das pessoas intersexuais, a possibilidade de o menor não ser submetido a cirurgias invasivas e a opção pelo acompanhamento psicológico representam contexto que encontra apoio no plano internacional, inclusive em documentos ratificados pelo Brasil. Além disso, ressalta-se o contido nos Princípios de Yogyakarta:

\footnotetext{
todas as pessoas têm o direito de desfrutar de todos os direitos humanos livres de discriminação por sua orientação sexual ou identidade de gênero. Todos e todas têm direito à igualdade perante à lei e à proteção da lei sem qualquer discriminação, seja ou não também afetado o gozo de outro direito humano. A lei deve proibir qualquer dessas discriminações e garantir a todas as pessoas proteção igual e eficaz contra qualquer uma dessas discriminações. (PRINCÍPIOS DE YOGYAKARTA, 2006).
}

Deste modo, a intersexualidade não deve ser vista como uma doença e sim como uma nova maneira de enxergar o mundo, devendo esta ser afastada de estereótipos há séculos concebidos e atualmente defasados, uma vez que os interesses do menor não podem ser sacrificados em prol da realização pessoal dos pais. Diante disto, a adoção do terceiro gênero como resposta à anomalia da diferenciação sexual é algo necessário para evitar que cirurgias sejam realizadas às pressas por uma questão de burocracia legal, visto que estas podem ser prejudiciais e atrapalhar o futuro desenvolvimento sexual e a identidade de gênero da criança.

Conforme compreendem Cardoso e Ferro (2012, p. 01), lamentavelmente, a população LGBT, devido a não adequação de gênero com o sexo biológico ou à identidade sexual não heteronormativa, "tem seus direitos humanos básicos agredidos, e muitas vezes se 
encontra em situação de vulnerabilidade", situação ainda mais severa em relação aos intersexuais, posto que os seus corpos são vistos como "anormais" e carentes de intervenção.

Logo, em um paralelo com a demanda transexual, vê-se que a pessoa que se identifica como tal possui o direito de exercer, plenamente, os seus direitos de escolha e de autodeterminação diante da possibilidade de submissão à cirurgia de adequação sexual, e/ou permissão para ostentar o nome e o gênero com os quais se identifica. Inclusive, em casos envolvendo menores, tem-se optado pelo direito da criança e do adolescente receberem acompanhamento psicológico adequado, no intento de preservar a liberdade de autodeterminação e minimizar ao máximo qualquer tipo de prejuízos ao desenvolvimento.

Em 2016, em decisão emblemática, a $3^{\text {a }}$ Vara Cível da Comarca de Sorriso, Estado do Mato Grosso, concedeu a uma criança trans o direito para alterar o seu nome e o gênero em documentos oficiais. Na ocasião, o menor foi representado pela Defensoria Pública. De acordo com reportagem divulgada pela BBC News:

[...] os documentos de Joana*\$, de 11 anos, representam um importante capítulo na vida dela e de sua família. Nos novos registros, atualizados há dois anos, constam o nome, que ela mesma escolheu, e o gênero: feminino. Joana tornou-se a primeira criança transgênero no Brasil a conseguir autorização na Justiça para que pudesse mudar seus documentos. (BBC NEWS, 2018).

Diante da proteção ao livre e pleno desenvolvimento da criança e do adolescente, caso os responsáveis legais obstem que o menor seja submetido ao devido acompanhamento, poderá o Judiciário, nestes casos, suprir, por meio de decisão judicial, a autorização dos pais e decidir em favor do melhor interesse do menor, em respeito ao disposto no art. 227 da Constituição Federal ${ }^{\S}$, que evidencia que o Poder Familiar é um direito-dever outorgado pelo Estado aos responsáveis legais. Deste modo, verifica-se que o Poder de Familiar possui como premissa a "garantia dos direitos fundamentais do menor, bem como uma forma de resguardar seu melhor interesse, tendo em vista que deve ser voltada exclusivamente para a promoção e o desenvolvimento da personalidade do filho". (TEIXEIRA; RODRIGUES, 2009, p. 85).

\footnotetext{
* Nome fictício atribuído pela própria reportagem para preservar o nome verdadeiro da criança.

$\S$ Art. 227, CF/88: "É dever da família, da sociedade e do Estado assegurar à criança, ao adolescente e ao jovem, com absoluta prioridade, o direito à vida, à saúde, à alimentação, à educação, ao lazer, à profissionalização, à cultura, à dignidade, ao respeito, à liberdade e à convivência familiar e comunitária, além de colocá-los a salvo de toda forma de negligência, discriminação, exploração, violência, crueldade e opressão.” (BRASIL, 1988).
} 
Nesta linha, mostra-se plausível o direito do menor intersexual de não sofrer intervenção cirúrgica logo após o nascimento e que, em contrapartida, é fundamental que a sua família também receba acompanhamento multidisciplinar, com o fito de proporcionar uma educação e ambiente acolhedor onde a criança consiga ter condições para se desenvolver e posicionar-se quanto ao seu corpo e identidade quando já for capaz de se manifestar e verbalizar as suas intenções.

Vale ressaltar que desde 1977, o Hospital Infantil Darcy Vargas, localizado em São Paulo/SP, realiza estudos voltados para a intersexualidade e presta serviço médico-psicológico adequado às pessoas intersexo e aos seus familiares. E, desde 2003, o Hospital das Clínicas da Faculdade de Medicina de Ribeirão Preto da Universidade de São Paulo e o Hospital Universitário de Brasília também têm desenvolvido trabalhos neste sentido. (SANTOS; ARAÚJO, 2003).

Salienta-se que, os apontamentos deste trabalho são singelos e, tão somente buscam elucidar a necessidade de reconhecimento do termo "terceiro gênero" como alternativa para a lavratura dos documentos das crianças intersexuais, na tentativa de reduzir, quiçá banir, as intervenções médicas cirúrgicas precipitadas quando a condição física não representar qualquer risco à vida ou à saúde do recém-nascido.

Do mais, a criação e o investimento por parte do Estado em clínicas especializadas em oferecer acompanhamento profissional adequado para as crianças de sexo não binário e aos seus familiares mostra-se como medida sensata e respeitosa. Por certo, o debate acerca das incertezas que rondam o campo da intersexualidade é extenso e muitos são os ângulos a serem observados. Todavia, isto não pode servir de óbice para que o Poder Judiciário se manifeste acerca do assunto e para que finalmente reconheça estes indivíduos como detentores de dignidade humana a ser preservada.

\section{CONSIDERAÇÕES FINAIS}

Diante de tudo o que foi demonstrado, vislumbra-se que as manifestações acerca da sexualidade e do gênero estão inseridas na sociedade desde os seus primórdios e, como tal, estão intrinsecamente ligadas à formação da personalidade. Ainda, é certo que em um Estado que busca ser reconhecido como Democrático de Direito, ter a dignidade da pessoa humana como cerne de todo o ordenamento é essencial para a eficaz proteção dos direitos humanos e de personalidade de seus cidadãos. 
Não obstante, em que pese o legislador brasileiro tenha optado pela inscrição “direitos da personalidade", o fato da Constituição Federal de 1988 adotar o princípio da dignidade da pessoa como elemento basilar para a formação do Estado implica no reconhecimento da teoria da cláusula geral dos direitos da personalidade. Diante disto, caberá ao ordenamento jurídico agir em prol da máxima proteção do indivíduo e, portanto, devem ser reconhecidos todos os direitos que se mostrarem essenciais ao livre desenvolvimento do ser humano. Sob esta ótica, o reconhecimento do terceiro gênero em documentos oficiais para os casos em que a pessoa é intersexual é medida de justiça que se impõe.

Pelo exposto, constata-se que a sujeição de um recém-nascido a uma cirurgia corretiva, a qual repercutirá durante toda sua vida, se mostra desproporcional e precipitada quando não evidenciado nenhum risco de vida. Isto porque, além dos riscos comuns inerentes a qualquer procedimento cirúrgico, esta intervenção médica releva-se invasiva e representa afronta à liberdade de escolha e de autodeterminação da criança que, no futuro, poderá a vir se identificar com o sexo oposto ao escolhido no momento da cirurgia corretiva.

A dificuldade em torno do reconhecimento das pessoas intersexuais está alicerçada na dicotomia homem e mulher e, portanto, não consegue aceitar aquilo que difere deste binarismo. A opção de pertencer ou não a qualquer gênero ou sexo deve ser uma decisão que compete apenas ao próprio indivíduo, direito que não pode ser limitado pelos seus representantes legais, médicos, tampouco pelo Estado, que deveria se preocupar em garantir a dignidade destas pessoas.

Desta forma, conclui-se que o reconhecimento do terceiro gênero nos casos de pessoas intersexuais pressupõe uma releitura do princípio da dignidade da pessoa como cláusula geral dos direitos da personalidade e, demonstrado que este é o posicionamento brasileiro, não há escusas que justifiquem a negativa a este direito.

\section{REFERÊNCIAS}

ASSOCIAÇÃO NACIONAL DOS REGISTRADORES DE PESSOAS NATURAIS (ARPEN BRASIL). Clipping - Jornal Deutsche Welle (Alemanha) - Onde o terceiro gênero é reconhecido no mundo. Disponível em: http://arpenbrasil.org.br/noticia/6024. Acesso em: 20 jun. 2019. 
BEAUVOIR, Simone de. O Segundo Sexo (1908 - 1986). 2. ed. Trad. Sérgio Milliet Rio de Janeiro: Nova Fronteira, 2009.

BÍBLIA, Antigo Testamento. Gênesis. In: BÍBLIA. Português. Bíblia Sagrada.

STORNIOLO, Ivo; BALANCIN, Euclides Martins (trad). São Paulo: Paulus, 2009.

BITTAR, Carlos Alberto. Os direitos da personalidade. 7. ed. Rio de Janeiro: Forense Universitária, 2004.

BITTAR, Carlos Eduardo Bianca. O direito na pós-modernidade. Revista Sequência, n. 57, p. 131-152, dez. 2008. Disponível em:

https://periodicos.ufsc.br/index.php/sequencia/article/viewFile/2177-

7055.2008v29n57p131/13642. Acesso em: 12 jun. 2019.

BOBBIO, Norberto; MATTEUCI, Nicola; PASQUINO, Gianfranco. Dicionário de Política, v. 1, 5. ed. Brasília: UnB e Imprensa Oficial do Estado, 2000.

BRASIL. Câmara dos Deputados. Projeto de Lei n ${ }^{\circ} 5255$ de 23 de maio de 2016.

Acrescenta $\S 4^{\circ}$ ao art. 54 da Lei $n^{\circ}$ 6.015, de 31 de dezembro de 1973, que "dispõe sobre os registros públicos, e dá outras providências", a fim de disciplinar o registro civil do recémnascido sob o estado de intersexo. Deputada Federal Laura Carneiro. Disponível em: https://www.camara.leg.br/proposicoesWeb/prop_mostrarintegra?codteor=1456906. Acesso em: 20 jun. 2019.

BRASIL. Supremo Tribunal Federal. Ação Direta de Inconstitucionalidade. ADI n. ${ }^{\circ}$ 4275/2018. Disponível em:

http://portal.stf.jus.br/processos/downloadPeca.asp?id=15339649246\&ext=.pdf. Acesso em: 20 jun. 2019.

BUTLER, Judith. Problemas de gênero: feminismo e subversão da identidade. Rio de janeiro: Civilização Brasileira, 2003.

CAÑIZARES, Emilio Benito de. OMS retira a transexualidade do rol de doenças mentais. El País, Madri, jun. 2018. Disponível em:

https://brasil.elpais.com/brasil/2018/06/18/internacional/1529346704_000097.html. Acesso em: 20 de jun. 2019.

CANTALI, Fernanda Borghetti. Direitos da personalidade: disponibilidade relativa, autonomia privada e dignidade humana. Porto Alegre: Livraria do Advogado, 2009.

CARDOSO, Michelle Rodrigues; FERRO, Luís Felipe. Saúde e população LGBT: demandas e especificidades em questão. Psicologia: Ciência e Profissão, v. 32, n. 3, p. 552-563, 2012. Disponível em: http://www.scielo.br/scielo.php?script=sci_arttext\&pid=S141498932012000300003\&lng=en\&nrm=iso\&tlng=pt. Acesso em: 02 jul. 2019.

CONSELHO FEDERAL DE MEDICINA (CFM). Resolução n. ${ }^{\circ} 1.664$ de 13 de maio de 2003. 2003. Define as normas técnicas necessárias para o tratamento de pacientes portadores de anomalias de diferenciação sexual. 2003. Disponível em: 
http://www.portalmedico.org.br/resolucoes/cfm/2003/1664_2003.htm. Acesso em: 20 jun. 2019.

CUPIS, Adriano de. Os direitos da personalidade. 2. ed. São Paulo: Quorum, 2008.

DECLARAÇÃO UNIVERSAL DOS DIREITOS HUMANOS. Assembleia Geral das Nações Unidas em Paris. 10 dez. 1948. Disponível em: https://nacoesunidas.org/wpcontent/uploads/2018/10/DUDH.pdf. Acesso em: 15 jun. 2019.

DIAS, Maria Berenice. Intersexo: aspectos jurídicos, internacionais, trabalhistas, registrais, médicos, psicológicos, sociais, culturais. In: DIAS, Maria Berenice (coord.). BARRETO, Fernanda Carvalho Leão (org.). Intersexo. São Paulo: Thomson Reuters Brasil, 2018.

GULLÓN, Antonio; DIÉZ-PICAZO, Luis. Sistema de Derecho Civil. Madri: Tecnos, 1988.

DINIZ, Maria Helena. Curso de direito civil brasileiro: Teoria Geral do Direito Civil. 28 ed. São Paulo, Editora Saraiva, 2011.

FEITOSA, Lourdes Conde. Gênero e sexualidade no mundo romano: a Antiguidade em nossos dias. História: Questões \& Debates, v. 48, 2008. Disponível em: https://revistas.ufpr.br/historia/article/view/15297/10288. Acesso em: 20 jun. 2019.

FRASER, Roberta Tourinho Dantas; LIMA, Isabel Maria Sampaio Oliveira. Intersexualidade e direito à identidade: uma discussão sobre o assentamento civil de crianças intersexuadas. Journal of Human Growth and Development, v. 22, n. 3, p. 1-7, 2012. Disponível em: http://pepsic.bvsalud.org/pdf/rbcdh/v22n3/pt_12.pdf. Acesso em: 31 jul. 2019.

GARCIA, Enéas Costa. Direito geral da personalidade no sistema jurídico brasileiro. São Paulo: Juarez de Oliveira, 2007.

HESPANHA, Antonio M. Panorama da Cultura Jurídica Européia. Lisboa: Publicações Europa-América, 1997. Disponível em: http://arpenbrasil.org.br/noticia/6024. Acesso em: 20 jun. 2019.

KUHN, Thomas Samuel. A estrutura das revoluções científicas. 5. ed. São Paulo: Perspectiva, 1997.

LEMOS, Vinícius. A história da primeira criança trans que conseguiu alterar os documentos no Brasil. BBC News, Cuiabá, 11 maio 2018. Disponível em: https://www.bbc.com/portuguese/brasil-44034765. Acesso em: 02 jul. 2019.

LENIN, Vladimir Ilitch. O Estado e a Revolução: o que ensina o marxismo sobre o Estado e o papel do proletariado na revolução. São Paulo: HUCITEC, 1986.

LOURO, Guacira Lopes. Currículo, género y sexualidade: lo "normal”, lo "diferente" y lo "excéntrico". Descentrada, v. 3, n 1, mar./ago. 2019. Disponível em: 
https://www.descentrada.fahce.unlp.edu.ar/article/view/DESe065/10437. Acesso em: 21 jun. 2019.

LOURO, Guacira Lopes. Gênero, sexualidade e educação: uma perspectiva pósestruturalista. Petrópolis: Vozes, 1997. Disponível em: https://www.mp.ba.gov.br/sites/default/files/biblioteca/direitos-humanos/direitos-dasmulheres/artigostesesdissertacoes/questoes_de_genero/guacira_lopes_genero_26_ago_15.pdf. Acesso em: 22 jun. 2019.

LUÑO, Antonio Enrique Perez. Los derechos fundamentales. 6. ed. Madri: Editorial Tecnos, 1995.

MEYER, Dagmar Estermann. Gênero e educação: teoria e política. In: Corpo, gênero e sexualidade: um debate contemporâneo na educação. LOURO, Guacira Lopes; NECKEL, Jane Felipe; GOELLner, Silvana Vilodre (org.). Petrópolis: Vozes, 2003.

MONTESQUIEU, Charles Louis de. Do Espírito das Leis. In: Coleção Os Pensadores Montesquieu. São Paulo, Abril Cultural, 1973.

POMPEU, Ana. STF autoriza pessoa trans a mudar nome mesmo sem cirurgia ou decisão judicial. Consultor Jurídico, 1 mar. 2018. Disponível em: https://www.conjur.com.br/2018mar-01/stf-autoriza-trans-mudar-nome-cirurgia-ou-decisao-judicial. Acesso em: 20 ago. 2019.

PRINCÍPIOS DE YOGYARKARTA. Princípios sobre a aplicação da legislação internacional de direitos humanos em relação à orientação sexual e identidade de gênero. 2015. Disponível em: http://www.clam.org.br/uploads/conteudo/principios_de_yogyakarta.pdf. Acesso em: 21 jun. 2019.

QUEIROGA, Louise. Brasil segue no primeiro lugar do ranking de assassinatos de transexuais. O Globo, São Paulo, 2018. Disponível em:

https://oglobo.globo.com/sociedade/brasil-segue-no-primeiro-lugar-do-ranking-deassassinatos-de-transexuais-23234780. Acesso em: 21 jun. 2019.

SANTOS, Moara de Medeiros Rocha; ARAUJO, Tereza Cristina Cavalcanti Ferreira de. A clínica da intersexualidade e seus desafios para os profissionais de saúde. Psicologia: Ciência e Profissão, v. 23, n. 3, p. 26-33, set. 2003. Disponível em:

http://www.scielo.br/scielo.php?script=sci_arttext\&pid=S1414-98932003000300005. Acesso em: 02 jul. 2019.

SARLET, Ingo Wolfang. Dignidade da pessoa humana e direitos fundamentais na Constituição Federal de 1988. 3. ed. Porto Alegre: Livraria do Advogado, 2004.

As dimensões da dignidade da pessoa humana: construindo uma compreensão jurídico-constitucional necessária e possível. In: (org.). Dimensões da Dignidade: Ensaios de Filosofia do Direito e Direito Constitucional. Porto Alegre: Livraria do Advogado, 2013. p. 13-43.

SARMENTO, Daniel. Direitos Fundamentais e Relações Privadas. Rio de Janeiro: Lumen Juris, 2004. 
SCHMITZ, Nicole Naiara; STEVANELLI, Wagner Garcia. Sexo Neutro: das adversidades ao reconhecimento do terceiro gênero. In: VIEIRA, Tereza Rodrigues (org.). Transgêneros. Brasília: Zakarewicz Editora, 2019. p. 393-402.

SCOTT, Joan Wallach. Gender: A Useful Category of Historical Analysis. The American Historical Review, v. 91, n. 5, p. 1053-1075, dez. 1986. Disponível em: http://www.jstor.org/stable/1864376. Acesso em: 21 jun. 2019.

SOUZA, Rabindranath Valentino Aleixo Capelo. O direito geral de personalidade. Coimbra: Coimbra, 1995.

SZANIAWSKI, Elimar. Direitos da personalidade e sua tutela. 2. ed. São Paulo: Revista dos Tribunais, 2005.

TEIXEIRA, Ana Carolina Brochado; RODRIGUES, Renata de Lima de. O direito das famílias entre a norma e a realidade. São Paulo: Atlas, 2010.

TEPEDINO, Gustavo. Temas de Direito Civil. 3. ed. Rio de Janeiro: Renovar, 2004.

THEDIM, Fernanda. Gêneros: Ser o que se é. Veja, São Paulo, 21 set. 2018.

Disponível em: https://veja.abril.com.br/50-ideias-para-50-anos/29-os-generos-ser-o-que-see/. Acesso em: 20 jun. 2018.

VENOSA, Silvio de Salvo. Direito Civil: parte geral. 11. ed. São Paulo: Atlas, 2011.

ZUCKER, Kenneth J. Intersexuality and gender identity differentiation. Journal of Pediatric and Adolescent Gynecology, v. 15, n. 1, p. 3-13, 2002. Disponível em:

https://www.researchgate.net/publication/12424470_Intersexuality_and_gender_identity_diff erentiation. Acesso em: 21 jun. 2019. 